\title{
Does Final Energy Demand in Portugal Exhibit Long Memory? A Fractional Integration Analysis ${ }^{(*)}$
}

\author{
José M. Belbute \\ Department of Economics, University of Évora, Portugal \\ Alfredo Marvão Pereira** \\ The College of William and Mary
}

College of William and Mary

Department of Economics

Working Paper Number 163

First Version: July 2015

This version: January 2016

(*) We would like to thank the participants of the $9^{\text {th }}$ Annual Meeting of the Portuguese Economic Journal (Azores, 2015), Rui Pereira for very helpful comments and suggestions, and Pedro Rodrigues for very competent editorial assistance. In addition, the first author would like to acknowledge financial support from FCT - Fundação para a Ciência e a Tecnologia and FEDER/COMPETE (grant PEst-C/EGE/UI4007/2013). 
COLLEGE OF WILLIAM AND MARY

DEPARTMENT OF ECONOMICS

WORKING PAPER \# 163

January 2016

\title{
Does Final Energy Demand in Portugal Exhibit Long Memory? A Fractional Integration Analysis
}

\begin{abstract}
In this paper, we measure the degree of fractional integration in final energy demand in Portugal using an ARFIMA model with and without adjustments for seasonality. We consider aggregate energy demand as well as final demand for petroleum, electricity, coal, and natural gas. Our findings suggest the presence of long memory in all of the energy demand variables. All fractional-difference parameters are positive and lower than 0.5 indicating that the series are stationary, although the mean reversion process will be slower than in the typical short run processes. These results have important implications for the design of energy policies. The effects of temporary policy shocks on final energy demand will tend to disappear slowly as a result of the long-memory process. This means that even transitory shocks have long lasting effects. Given the temporary nature of these effects, however, permanent effects on final energy demand require permanent policies. This is unlike what would be suggested by the more standard but much more limited unit root approach, which would incorrectly indicate that even transitory policies would have permanent effects.
\end{abstract}

Keywords: $\quad$ Long memory, final energy demand, ARFIMA model, Portugal.

JEL Codes: $\quad$ C22, O13, Q41.

José M. Belbute

Department of Economics, University of Évora, Portugal

Center for Advanced Studies in Management and Economics - CEFAGE, Portugal

jbelbute@uevora.pt

Alfredo Marvão Pereira

Department of Economics, The College of William and Mary, Williamsburg, USA

PO Box 8795, Williamsburg, VA 23187

ampere@wm.edu 


\section{Does Final Energy Demand in Portugal Exhibit Long Memory? A Fractional Integration Analysis}

\section{Introduction}

Understanding persistence in final energy demand is crucial for the design, the implementation, and the effectiveness of the energy and environmental policies. First, if energy consumption is stationary, then public policies that promote energy efficiency, fuel switching or reductions in greenhouse gas emissions, will tend to have transitory effects, thereby requiring a permanent policy stance [see, Lean and Smyth (2009), Gil-Alana et al. (2010), and Apergis and Tsoumas (2012)]. Second, a low degree of persistence means that energy consumption returns to its trend path after a shock so that past behavior can appropriately be used to predict future energy consumption [see Lean and Smyth (2009) and Smyth (2012)]. Finally, given the strong connection of the energy sector to the rest of the economy, if the effects of shocks to energy consumption are transitory but last long then such effects may be transmitted to other sectors of the economy as well as to macroeconomic variables [see Lean e Smyth (2009), Gil-Alana et al. (2010)].

There is a vast literature using traditional autoregressive univariate unit roots methods to test the stationary properties of energy variables [see, for example, Altinay and Karagol (2004), Lee and Chang $(2005,2008)$, Narayan and Smyth $(2005,2007)$, Hsu and Lee (2008), Lee and Lee (2009), Narayan et al. (2008) and Smyth (2012)]. Recent evidence with panel data tests that accommodate structural breaks provide strong support for the stationarity of energy consumption and production.

Traditional autoregressive univariate unit root tests, however, are limited to the stationary/non-stationary dichotomy. Their power to reject the null hypothesis depends on several factors such as structural breaks, non-linearities, and the existence of long memory or fractional integration, all of them likely to affect energy variables [see, for example, Narayan and Smyth (2007), Hasanov and Telatar (2011), Apergis and Payne (2010), Narayan et al. (2010), Aslan and Kum (2011)]. More importantly 
from our perspective, the unit root tests only provide evidence about the existence or absence of a permanent component but not its extent. That is, the unit root test only confirms that the current value of a variable is determined by its past behavior but is unable to identify how distant in time that influence extends.

There is now a growing literature on fractional integration going beyond the stationary/non-stationary dichotomy to consider the possibility that variables may follow a long memory process [see, for example, Palma (2007)]. This long range dependence is characterized by a hyperbolically decaying autocovariance function and by a spectral density that tends to infinity as frequency tends to zero. The intensity of this phenomena can be measured by a differencing parameter " $d$ ", which includes the stationary case $(d=0)$ and the non-stationary case $(d=1)$ as particular cases. When $d<1$ the process is mean reverting. For $0.5<d<1$, the process is not covariance stationary thought mean reverting. When $-0.5<d<0.5$ the process is said to be covariance stationary and ergodic with a bounded and positively value spectrum at all frequencies. When $-0.5<d<0$ the process is called intermediate memory or over differenced. In turn, when $0<d<0.5$, the process is stationary but displays long memory in the sense that its autocorrelation function decay exponentially, rather than geometrically as in the case of short memory $(d=0)$.

In this context, long memory represents an important and nuanced situation that goes beyond the stationary/non-stationary paradigm. It reflects a significant dependence between observations widely separated in time. Therefore, the effects of shocks, although mean reverting, tend to decay slowly. From a policy perspective, the existence of long memory implies that the effects of transitory policies are long-lasting. It also implies that such effects are transitory and, therefore, that the only way to achieve permanent effects is to adopt permanent policies. By contrast, the traditional stationary/non-stationary dichotomy would suggest that the effects of transitory policies are either short-lived (stationary case) or permanent (non-stationary case). This more rigid approach is bound to lead to misleading policy implications by either identifying short lived effects where the effects may actually be long lasting or by identifying as permanent, effects that may actually be mean reverting. 
Despite its widespread use in the general economics literature ${ }^{1}$, only recently has the presence of long range dependence been tested in the energy literature [see for example, Elder and Serletis (2008), Gil-Alana et al. (2010), Apergis and Tsoumas (2011 and 2012), Barros et al. (2012a and 2002b), and Belbute and Pereira (2015a and 2015b]]. The results from these fractional integration tests generally confirm that energy variables are stationary but exhibit long term memory, with the resulting implications for policy suggested above.

The energy literature on long memory properties has focused almost invariably on total energy consumption and on the case of the United States. The absence of evidence on the degree of long range dependence in other advanced countries and on the relative levels of persistence among different forms of final energy demand is an important void in the literature. This is a void that we intend to start filling with this paper by concentrating on the case of final energy demand in Portugal and by considering not only final energy demand but also its major components.

Indeed, in this paper we measure the degree of fractional integration in final energy demand in Portugal considering both aggregate final energy demand and its four main components - petroleum and its derivatives, electricity, coal, and natural gas. We use an autoregressive moving average fractionally integrated, ARFIMA, model approach. An ARFIMA model is a generalization of the ARIMA model which frees it from the stationary versus non-stationary dichotomy. We consider monthly data starting in early 1985 and use both the original data and its seasonally adjusted version to test for fractional integration.

This paper is not the first looking into the general issue of persistence in energy demand in Portugal. A previous, albeit tentative, analysis can be found in Belbute and Pereira (2014). There, the issue is approached in very general terms using annual energy consumption data and a non-parametric approach. The present paper brings much greater focus and clarity to the issue both in scope and in approach and,

\footnotetext{
${ }^{1}$ See, for example, Diebold and Rudebush (1989), Lo (1991), Backus and Zin (1993); Cheung (1993), Willinger, Taqqu and Teverovsky (1999), Gil-Alana (2002), Dijk, Hans, and Paap (2002), Caporale and Gil-Alana (2004), Sinclair (2005), Yoon, G (2009), Gil-Alana (2010), Aloy, Boutahar, Gente and Feissolle (2011), Bos, C. S. Koopman and M. Ooms (2014), for applications in the area of GDP, unemployment, inflation, exchange rates, and stock market prices.
} 
therefore, to the meaning and precision of the findings. It does so, first, by using a much expanded monthly data set which allows for a deeper, more nuanced and more robust analysis. Second, it uses a fractional integration approach, which by its very nature, allows for a clear identification of the type of memory that characterizes the different types of energy demand going well beyond the traditional stationary/nonstationary dichotomy.

The paper is organized as follows. Section 2 presents the data set. Section 3 provides a brief technical description. Section 4 discusses the empirical evidence. Finally, section 5 provides a summary of the results and discusses their policy implications.

\section{Data: Sources and Description}

This work uses monthly data for gross inland energy consumption (GIEC, hereafter). According to the Eurostat, GIEC is the total energy demand and it represents the quantity of energy necessary to satisfy consumption of the geographical entity under consideration. It covers four components; a) consumption by the energy sector itself; b) distribution and transformation losses; c) final energy consumption by end users and d) "statistical differences" (not already captured in the figures on primary energy consumption and final energy consumption). Eurostat computes GIEC as the sum of primary production, recovered products, net imports and variations of stocks, minus

bunkers. Moreover, consumption by the energy sector includes the energy consumption by the sector itself in refineries, in electric power plants, transport losses and the consumption with hydroelectric pumping.

All data comes from the Eurostat's web site which, in turn, are based on data from the Portuguese Department of Energy. They clearly reflect the distinction between primary and final energy demand. Primary energy is defined as the energy found in nature that has not been subjected to any conversion or transformation process but it is used to produce other forms of energy.

GIEC for Portugal includes four energy components: petroleum and its derivatives, electricity, natural gas and coal. GIEC data for Portugal covers the period from February 1985 until December 2011 (which corresponds to 232 observations). In the case of natural gas, the starting date is February 1997 (which corresponds to 179 
observations), the date when the necessary distribution infrastructure was completed thereby allowing natural gas to become an important component of the Portuguese energy system. All variables are expressed in $10^{3}$ tons of oil equivalent (ktoe hereafter), and were converted into natural logarithms for the empirical analysis. The original data are not seasonally adjusted. See Table 1 for details.

Final demand of petroleum and derivatives includes crude oil and all derivatives that are used exclusively as a primary energy source such as diesel, fuel oil, gasoline, liquefied petroleum gas, naphtha, kerosene, and petroleum coke. Petroleum and its derivatives used as raw materials in the production of, for example, lubricants, of asphalt, paraffin, solvents and propylene are not considered in our data. Petroleum and its derivatives account for $66.0 \%$ of total energy demand in Portugal, although this share showed a declining trend over the sample period. In 2011 the final demand of petroleum and derivatives represented $53.7 \%$ of total energy demand.

Final demand for electricity does not distinguish among production technologies or the raw material used in electricity generation, with the exception of co-generation (that is, combined heat and power stations) and heat (that is, electricity produced by plants which are designed to produce heat only), which are accounted for separately by Eurostat. It represents $13.0 \%$ of total final energy demand for the entire sample period but has increased consistently in the last part of the sample period. In 2011 the final demand for electricity represented $15.6 \%$ of total energy demand.

Final demand for coal includes domestic production and imports of hard coal, anthracite and coke coal. It constitutes $14.1 \%$ of total final energy demand for the sample period but with a decreasing trend over the last part of the sample period. It represented $10.2 \%$ of total energy demand in 2011.

Final demand for natural gas consists of the imports of both natural gas transported by pipeline and liquefied natural gas shipped by vessels. In 1997 the country began an important program devoted to the development of a natural gas distribution infrastructure which rapidly stimulated its consumption. After its introduction, the consumption of natural gas grew very rapidly. Its share of final energy demand was just $2.8 \%$ in 1998 and reached $20.5 \%$ in 2011. The average over the sample period was 
Table 1 - Aggregate Inland Energy Consumption in Portugal

\begin{tabular}{|c|c|c|c|c|c|}
\hline & \multirow{2}{*}{$\begin{array}{l}\text { Aggregate Inland } \\
\text { Energy } \\
\text { Consumption: } \\
\text { monthly average } \\
\text { (ktoe) }\end{array}$} & \multicolumn{4}{|c|}{ Shares } \\
\hline & & $\begin{array}{l}\text { Petroleum } \\
\text { (\%) }\end{array}$ & $\begin{array}{l}\text { Electricity } \\
\text { (\%) }\end{array}$ & $\begin{array}{l}\text { Coal } \\
(\%)\end{array}$ & $\begin{array}{l}\text { Gas } \\
(\%)\end{array}$ \\
\hline 1985 & 6.810 & 0.744 & 0.142 & 0.114 & - \\
\hline 1986 & 6.864 & 0.747 & 0.147 & 0.106 & - \\
\hline 1987 & 6.947 & 0.736 & 0.134 & 0.131 & - \\
\hline 1988 & 7.033 & 0.711 & 0.137 & 0.151 & - \\
\hline 1989 & 7.223 & 0.723 & 0.127 & 0.149 & - \\
\hline 1990 & 7.251 & 0.701 & 0.137 & 0.163 & - \\
\hline 1991 & 7.257 & 0.709 & 0.142 & 0.149 & - \\
\hline 1992 & 7.360 & 0.712 & 0.126 & 0.161 & - \\
\hline 1993 & 7.333 & 0.693 & 0.132 & 0.175 & - \\
\hline 1994 & 7.329 & 0.703 & 0.125 & 0.172 & - \\
\hline 1995 & 7.414 & 0.701 & 0.119 & 0.179 & - \\
\hline 1996 & 7.355 & 0.699 & 0.132 & 0.169 & - \\
\hline 1997 & 7.417 & 0.704 & 0.119 & 0.173 & 0.004 \\
\hline 1998 & 7.512 & 0.712 & 0.123 & 0.138 & 0.028 \\
\hline 1999 & 7.635 & 0.649 & 0.120 & 0.154 & 0.078 \\
\hline 2000 & 7.622 & 0.634 & 0.124 & 0.157 & 0.086 \\
\hline 2001 & 7.625 & 0.650 & 0.132 & 0.126 & 0.091 \\
\hline 2002 & 7.651 & 0.653 & 0.123 & 0.117 & 0.108 \\
\hline 2003 & 7.633 & 0.621 & 0.126 & 0.147 & 0.106 \\
\hline 2004 & 7.650 & 0.618 & 0.118 & 0.133 & 0.131 \\
\hline 2005 & 7.718 & 0.595 & 0.111 & 0.154 & 0.139 \\
\hline 2006 & 7.629 & 0.580 & 0.124 & 0.149 & 0.146 \\
\hline 2007 & 7.592 & 0.603 & 0.119 & 0.119 & 0.159 \\
\hline 2008 & 7.538 & 0.593 & 0.115 & 0.110 & 0.183 \\
\hline 2009 & 7.533 & 0.546 & 0.141 & 0.126 & 0.187 \\
\hline 2010 & 7.527 & 0.569 & 0.159 & 0.073 & 0.199 \\
\hline 2011 & 7.498 & 0.537 & 0.156 & 0.102 & 0.205 \\
\hline \multicolumn{6}{|c|}{ Sample Descriptive Statistics } \\
\hline$\mu$ & 7.408 & 0.660 & 0.130 & 0.141 & 0.069 \\
\hline$\sigma_{\mu}$ & 0.015 & 0.004 & 0.001 & 0.002 & 0.004 \\
\hline$\sigma_{\mu} / \mu$ & $0.20 \%$ & $0.59 \%$ & $0.88 \%$ & $1.68 \%$ & $3.53 \%$ \\
\hline
\end{tabular}

Note: $\mu$ stands for the mean, $\sigma_{\mu}$ stand for the standard deviation of the mean and $\sigma_{\mu} / \mu$ stands for the coefficient of variation.

just $6.9 \%$ which naturally reflects its total absence in the final energy mix prior to 1997.

Overall, over the sample period, we observe a declining trend in the final demand for petroleum and its derivatives and coal while the opposite is true for electricity and 
natural gas. Yet, petroleum and its derivatives continue to account for more than half of the final demand for energy.

\section{Fractional Integration}

\subsection{Fractionally integrated processes}

A fractionally integrated process is a stochastic process whose degree of integration is a fractional number and whose autocorrelation function exhibits persistence which is neither an $\mathrm{I}(0)$ nor an $\mathrm{I}(1)$ process. Nevertheless, persistence is consistent with a stationary process where the autocorrelations decay hyperbolically. Because the autocorrelations die out slowly, the fractionally integrated processes display long-run, rather than short-term dependence, and for that reason are also known as longmemory processes [See, for example, Granger and Joyeux (1980), Granger (1980, 1981), Sowell (1992a, 1992b), Baillie (1996) and Palma (2007).

A time series $x_{t}=y_{t}-\beta z_{t}$ - where $\beta$ is the coefficients vector, $z_{t}$ represents all deterministic factors of the process $y_{t}$ and $t=1,2, \ldots n$ - is said to be fractionally integrated of order $d$ if it can be represented by

$$
(1-L)^{d} x_{t}=u_{t}, \quad t=1,2,3, \ldots
$$

where, $L$ is the lag operator, $d$ is a real number that captures the long-run effect and $u_{t}$ is $I(0)$.

Through binomial expansion, the filter $(1-L)^{d}$ provides an infinite-order $L$ polynomial with slowly and monotonically declining weights,

$(1-L)^{d}=\sum_{j=0}^{\infty}\left(\begin{array}{l}d \\ j\end{array}\right)(-1)^{j} L^{j}=1-d L+\frac{d(d-1)}{2 !} L^{2}-\frac{d(d-1)(d-2)}{3 !} L^{3}+\cdots$

and thus (1) can be written as:

$$
x_{t}=d x_{t-1}-\frac{d(d-1)}{2} x_{t-2}+\frac{d(d-1)(d-2)}{3 !} x_{t-3}+\cdots u_{t}
$$

If $d$ is an integer, then $x_{t}$ is a function of a finite number of past observations. In particular, if $d=1$, then $x_{t}$ is a unit root non-stationary process and, therefore, the 
effect of a random shock is exactly permanent. If $d=0$, then $x_{t}=u_{t}$ and the time series is $I(0)$, weakly auto-correlated (or dependent) with auto-covariances decaying exponentially. More formally,

$$
\gamma_{j}=\alpha_{1}{ }^{j}, \quad \text { for } \quad j=1,2, \ldots \text { and }\left|\alpha_{1}\right|<1
$$

Allowing $d$ to be a real number provides a richer degree of flexibility in the specification of the dynamic nature of the series, and depending on the value of the parameter $d$ we can determine different levels of intertemporal dependency. In fact, when $d$ is a non-integer number, each $x_{t}$ depends on its past values far away back in time. Moreover, the auto-covariance function satisfies the following property

$$
\gamma_{j} \approx c_{1} j^{2 d-1}, \quad \text { for } j=1,2, \ldots \text { and } 0<\left|c_{1}\right|<\infty
$$

where " $\approx$ " means that the ratio between the two sides of $(5)$ will tend to unity as $j \rightarrow \infty$. Assuming that the process $x_{t}$ has a spectral distribution such that the density function $f(\lambda)$ is given by,

$$
f(\lambda)=\left(\frac{\sigma^{2}}{2 \pi}\right)\left|\frac{\theta\left(e^{-i \lambda}\right)}{\phi\left(e^{-i \lambda}\right)}\right|^{2}\left[2(1-\cos (\lambda)]^{-2 d}\right.
$$

then for low frequencies as $\lambda \rightarrow 0^{+}$we get

$$
f(\lambda) \approx c_{2} \lambda^{-2 d}
$$

Where $c_{2}=\left(\frac{\sigma^{2}}{2 \pi}\right)\left|\frac{\theta(1)}{\phi(1)}\right|^{2}>0$ and " $\approx$ " means that the ratio between the two sides of (7) will tend to unity as $\lambda \rightarrow 0^{+}$.

In general, larger values for the fractional-difference parameter, $d$, indicate a greater degree of persistence. Specifically, if $-0.5<d<0$, the autocorrelation function decays at a slower hyperbolic rate but the process can be called anti-persistent, or, alternatively, to have rebounding behavior or negative correlation. If $0<d<0.5$, the process reverts to its mean but the auto-covariance function decreases slowly as a result of the strong dependence on past values. Nevertheless, the effects will last longer than in the pure stationary case $(d=0)$. If $0.5<d<1$, the process is non- 
stationary with a time-dependent variance, but the series retains its mean-reverting property. Finally, if $d \geq 1$, the process is non-stationary and non-mean-reverting, i.e. the effects of random shocks are permanent.

\subsection{ARFIMA processes}

An auto-regressive fractionally integrated moving average process, ARFIMA, is an extension of the traditional ARIMA model allowing for fractional degrees of integration. The autocorrelations of the ARFIMA process decay in a slower rate than the exponential rate associated with the ARMA process and, generally, with short memory processes. ARFIMA models were first introduced by Granger and Joyeux (1980) and Granger $(1980,1981)$ to solve problems to unit roots tests caused by either variable aggregation, and more recently, by the duration of shocks [see, for example, Sowell (1992a, 1992b), Baillie (1996) and Palma (2007), for reviews of this literature].

A process like (1) is called fractionally integrated of order $d$ if $d$ is a non-integer. If, in addition, $u_{t}$ in (1) is an $\operatorname{ARMA}(p, q)$, then $x_{t}$ is an ARFIMA process becomes,

$$
\phi(L)(1-L)^{d} x_{t}=\theta(L) e_{t}
$$

where $\phi(L)$ and $\theta(L)$ are the polynomials of order $p$ and $q$ respectivelly, with all zeroes of $\phi(L)$ and $\theta(L)$ given, respectively, by

$$
\begin{gathered}
\phi(L)=1-\phi_{1} L-\phi_{2} L^{2}-\ldots-\phi_{p} L^{p}=0 \\
\theta(L)=1+\theta_{1} L+\theta_{2} L^{2}+\ldots+\theta_{p} L^{q}=0
\end{gathered}
$$

lying outside the unit circle, and $e_{t}$ is white noise. Clearly, the process is stationary and invertible for $-0.5<d<0.5$.

The estimation of the parameters of the ARFIMA model is done by the method of maximum likelihood. The log Gaussian likelihood was established by Sowell (1992b) and is

$$
\ell((y \mid \hat{\eta}))=-\frac{1}{2}\left\{\boldsymbol{T} \log (2 \pi)+\log |\widehat{\boldsymbol{V}}|+(\boldsymbol{y}-\boldsymbol{X} \widehat{\boldsymbol{\beta}})^{\prime} \widehat{\boldsymbol{V}}^{-1}(\boldsymbol{y}-\boldsymbol{X} \widehat{\boldsymbol{\beta}})\right\}
$$

The covariance matrix $\boldsymbol{V}$ has a Toeplitz structure: 


$$
\boldsymbol{V}=\left[\begin{array}{ccccc}
\gamma_{0} & \gamma_{1} & \gamma_{2} & \ldots & \gamma_{T-1} \\
\gamma_{1} & \gamma_{0} & \gamma_{1} & \ldots & \gamma_{T-2} \\
\gamma_{2} & \gamma_{1} & \gamma_{0} & \ldots & \gamma_{T-3} \\
\vdots & \vdots & \vdots & \ddots & \vdots \\
\gamma_{T-1} & \gamma_{T-2} & \gamma_{T-3} & \ldots & \gamma_{0}
\end{array}\right]
$$

where, $\gamma_{0}=\operatorname{Var}\left(y_{t}\right)$ and $\gamma_{j}=\operatorname{Cov}\left(y_{t}, y_{t-1}\right)$ for $j=1,2, \ldots t-1$ and $t=1,2, \ldots T$.

\subsection{A seasonal long-memory process}

A seasonal white noise parametric long-memory process has been proposed by PorterHudak (1990) who considers a simple seasonally fractionally differenced process as

$$
\left(1-L^{s}\right)^{d} x_{t}=u_{t}, \quad t=1,2,3, \ldots
$$

where, $s$ is the seasonal period and $L^{s} x_{t}=x_{t-s}$. As with (2), the process also will have an infinite-order $L^{s}$ polynomial with slowly and monotonically declining weights,

$$
\left(1-L^{s}\right)^{d}=\sum_{j=0}^{\infty}\left(\begin{array}{l}
d \\
j
\end{array}\right)(-1)^{j} L^{s j}=1-d L+\frac{d(d-1)}{2 !} L^{2 s}-\frac{d(d-1)(d-2)}{3 !} L^{3 s}+\cdots
$$

A more general seasonal ARFIMA model, can be written as

$$
\phi(L)\left(1-L^{s}\right)^{d_{s}} x_{t}=\theta(L) e_{t}
$$

The spectrum of the seasonal ARFIMA model is given by Porter-Hudak (1990) and Ray (1993) as

$$
f(\lambda)=\left(\frac{\sigma^{2}}{2 \pi}\right)\left|\frac{\theta\left(e^{-i \lambda}\right)}{\phi\left(e^{-i \lambda}\right)}\right|^{2}\left[2(1-\cos (s \lambda)]^{-2 d}\right.
$$

The spectrum is unbounded at frequencies $\lambda_{j}=\frac{(2 \pi j)}{s}$, for $j=0,1,2, \ldots s / 2$, so that the model contains a persistent trend and a $(\mathrm{s} / 2)$ persistent cyclical component. Hence the seasonal ARFIMA process shows a behavior at seasonal frequencies similar to that of the ARFIMA process at zero frequency (6).

In particular, we will use the twelfth seasonal difference $\left(S 12 y_{t}=y_{t}-y_{t-12}=\right.$ $\left(1-L^{12}\right) y_{t}$ of the natural logs of the series $\left(y_{t}=\ln \left(x_{t}\right)\right)$ and the seasonal ARFIMA model can be written as

$$
\phi(L)\left(1-L^{12}\right)^{d_{s}} y_{t}=\theta(L) e_{t}
$$


Accordingly, seasonality has long memory when $0<d_{s}<0.5$ and the short-run dynamics are described through the estimation of the $\rho$ parameter of the usual nonseasonal $A R(p)$ part of (17).

\section{The Empirical Results}

In this section, we present the main empirical results. The bulk of this section deals with the estimation of different $\operatorname{ARFIMA}(p, d, q)$ models using natural logarithms of the raw data. We consider three empirical approaches, first using the raw data in logs

without any modifications' second, using the raw data in logs but with seasonality filtered out; and third, with the data corrected for seasonality.

As a starting point of reference and for the sake of highlighting the insights brought forth by the fractional integration approach, we begin by considering the results from the standard unit roots tests, i.e., the tests that only consider the dichotomy between stationarity and non-stationarity. The results are traditionally interpreted as suggesting that the effects of one-time shocks to the series are either transitory, if the series is stationary, or permanent if the series is not stationary.

\subsection{The Traditional Approach: Standard Unit Roots Tests}

We use the Augmented Dickey-Fuller (ADF) t-test to test the null hypothesis of a unit root in aggregate energy consumption and its components in log differences. The optimal lag structure is chosen using the Schwartz Bayesian Information Criterion (BIC) as the model selection criteria, and the deterministic component (DET hereafter) were included if statistically significant.

The test results are presented in Table 2 and suggest that all series under consideration are non-stationary in log-levels but stationary in first log-differences, that is, they are I(1). Based on these test results we can conclude that one-time shocks to all of these series have permanent effects on the levels of the different variables. This means that the one-off policy shocks have permanent effects and that maintaining a steady policy stance is not critical, since even one-time shocks will lead to permanent effects. In addition, there is nothing we can say based on these results 
Table 2 - Traditional unit root results for energy consumption

\begin{tabular}{|c|c|c|c|c|c|c|}
\hline Variables & DET & Lag & $\mathbf{t}$ & $p$-value & & BIC \\
\hline \multicolumn{7}{|l|}{ In log-levels } \\
\hline Aggregate energy consumption & Constant and trend & 1 & 0.625 & 0.851 & & -614.931 \\
\hline Oil & Constant & 2 & 0.218 & 0.750 & & -605.98 \\
\hline Coal & Constant & 2 & -0.108 & 0.646 & & 311.39 \\
\hline Gas & Constant and trend & 5 & 0.270 & 0.765 & & -85.6854 \\
\hline Electricity & Constant and trend & 4 & 0.702 & 0.867 & & -550.573 \\
\hline \multicolumn{7}{|l|}{ In log-differences } \\
\hline Aggregate energy consumption & None & 1 & -17.714 & 0.000 & $* * *$ & -620.305 \\
\hline Oil & None & 1 & -19.179 & 0.000 & $* * *$ & -611.701 \\
\hline Coal & None & 5 & -11.621 & 0.000 & $* * *$ & 286.262 \\
\hline Gas & None & 4 & -8.027 & 0.000 & $* * *$ & -90.763 \\
\hline Electricity & None & 6 & -10.046 & 0.000 & $* * *$ & -606.782 \\
\hline
\end{tabular}

on the relative degree of persistence of the different components of energy consumption.

It is also interesting to note that these results coincide with the directly-related literature on stationarity/non-stationarity in energy consumption to confirm the presence of unit roots. Furthermore, even the evidence using a fractional integration approach suggests that unit roots are prevalent [see, among others Gil-Alana et all (2012) and 2010), Apergis and Tsoumas (2011) or Lean and Smyth (2009)].

\subsection{Fractional integration without seasonal adjustments}

In all cases that follow, the optimal ARFIMA structure was chosen using the Schwartz Bayesian Information Criterion (BIC) as the model selection criteria. We present the estimation results of the auto-regressive and moving average components that correspond to the optimal specification ${ }^{2}$, as well as of the estimated fractional integration parameter $d$. For each estimated parameter we present the corresponding standard errors, $\mathrm{p}$-values and $95 \%$ confidence intervals.

Results for the fractional integration analysis without any consideration of seasonality are presented in Table 3 . These results suggest that there is statistically significant evidence for the non-rejection of the presence of long memory in aggregate energy demand as well as in its four components.

\footnotetext{
${ }^{2}$ Only the parameters corresponding to the optimal ARMA structure are reported. Specifically, if the optimal structure is $A R(12)$ or $M A(12)$ all coefficients will be reported. If, however, only the $12^{\text {th }}$ order coefficients are significant, then only these coefficients are reported.
} 
Table 3 - Fractional integration results without seasonal adjustments

\begin{tabular}{|c|c|c|c|c|c|c|c|}
\hline & & \multirow{2}{*}{ Constant } & \multicolumn{2}{|r|}{$A R()$} & \multirow{2}{*}{$\frac{\mathrm{FI}()}{\widehat{d}}$} & \multicolumn{2}{|r|}{ MA() } \\
\hline & & & $p$ & $\widehat{\boldsymbol{\rho}}$ & & $q$ & $\widehat{\boldsymbol{\theta}}$ \\
\hline $\begin{array}{l}\text { Aggregate } \\
\text { energy } \\
\text { consumption }\end{array}$ & $\begin{array}{l}\text { Standard error } \\
\text { p-value } \\
\text { Conf. Interval (95\%) } \\
\text { BIC } \\
\end{array}$ & $\begin{array}{c}7.1348 \\
1.5475 \\
0.000 \\
{[4,1017 ; 10,1679]}\end{array}$ & 12 & $\begin{array}{c}0.9524 \\
0.0237 \\
0.000 \\
{[0,9059 ; 0,9988]} \\
-6\end{array}$ & $\begin{array}{c}0.4913 \\
0.0117 \\
0.000 \\
{[0,4685 ; 0,5141]} \\
075 \\
\end{array}$ & 12 & $\begin{array}{c}-0.7852 \\
0.0527 \\
0.000 \\
{[-0,8884 ;-0,6819]}\end{array}$ \\
\hline $\begin{array}{c}\text { Petroleum and } \\
\text { derivatives }\end{array}$ & $\begin{array}{l}\text { Standard error } \\
\text { p-value } \\
\text { Conf. Interval (95\%) } \\
\text { BIC }\end{array}$ & $\begin{array}{c}6.8700 \\
0.4436 \\
0.000 \\
{[6,0005 ; 7,7395]}\end{array}$ & 12 & $\begin{array}{c}0.3107 \\
0.05916 \\
0.000 \\
{[0,19448 ; 0,4267]} \\
-6\end{array}$ & $\begin{array}{c}0.4875 \\
0.016 \\
0.000 \\
{[0,4562 ; 0,5187]} \\
474 . \\
\end{array}$ & 0 & \\
\hline Electricity & $\begin{array}{l}\text { Standard error } \\
\text { p-value } \\
\text { Conf. Interval (95\%) } \\
\text { BIC }\end{array}$ & $\begin{array}{c}5.328 \\
0.3464 \\
0.000 \\
{[4,6491 ; 6,0069]}\end{array}$ & 12 & $\begin{array}{c}0.2744 \\
0.0634 \\
0.000 \\
{[0,1502 ; 0,3986]} \\
-5 \\
\end{array}$ & $\begin{array}{c}0.4803 \\
0.0256 \\
0.000 \\
{[0,4301 ; 0,5305]} \\
339\end{array}$ & 0 & \\
\hline Coal & $\begin{array}{l}\text { Standard error } \\
\text { p-value } \\
\text { Conf. Interval (95\%) } \\
\text { BIC } \\
\end{array}$ & $\begin{array}{c}5.049 \\
0.7616 \\
0.000 \\
{[3,5560 ; 6,5415]}\end{array}$ & 12 & $\begin{array}{c}0.8674 \\
0.092 \\
0.000 \\
{[0,6870 ; 1,0478]} \\
\end{array}$ & $\begin{array}{c}0.4233 \\
0.0428 \\
0.000 \\
{[0,3393 ; 0,5073]} \\
87 \\
\end{array}$ & 12 & $\begin{array}{c}-0.7155 \\
0.1323 \\
0.000 \\
{[-0,9749 ;-0,4562]}\end{array}$ \\
\hline Gas & $\begin{array}{l}\text { Standard error } \\
\text { p-value } \\
\text { Conf. Interval (95\%) } \\
\\
\text { Standard error } \\
\text { p-value } \\
\text { Conf. Interval (95\%) } \\
\text { BIC }\end{array}$ & & 1 & $\begin{array}{c}0.7598 \\
0.1137 \\
0.000 \\
{[0,5369 ; 0,9827]} \\
\\
0.2255 \\
0.1083 \\
0.037 \\
{[0,0132 ; 0,4379]} \\
1 \\
\end{array}$ & $\begin{array}{c}0.2814 \\
0.0956 \\
0.003 \\
{[0,0942 ; 0,4686]}\end{array}$ & & \\
\hline
\end{tabular}

Note: $\hat{\rho}$ stands for the estimated value of the parameter associated with $x_{t-p}$ of the AR component and $\hat{\theta}$ stands for the estimated value of the stochastic term of order $q\left(e_{t-q}\right)$ of the MA component.

All the estimates of the fractional parameter $d$ are in the range $(0,1)$ thus allowing us to reject both the pure stationary case $(d=0)$ and the unit root model $(d=1)$. More specifically, all estimated parameters $d$ are statistically significant at the $5 \%$ level test and lie within the interval $(0,0.5)$. Petroleum and electricity show the highest degrees of persistence ( $d=0.4875$ and $d=0.4803$ ) closely followed by coal ( $d=0.4233$ ). For the case of final demand for gas, the value of the fractional integration parameter $(d=0.2814)$ is lower than for the other final energy demand variables, suggesting a weaker intensity of persistence for this component, though stronger than the pure stationary case.

Overall, these results mean that the effects of a random shock in the innovations of these series are transitory as the series are mean reverting. Such effects, however, will last longer than in the pure stationary case. These series, therefore, exhibit longmemory behavior.

The confidence intervals for the estimated fractional integration parameters are sometimes wide but always in the positive range. Also, with the exception of natural 
gas, the upper bounds are slightly greater than 0.5 leaving open the possibility that these series may be non-stationary, though mean-reverting.

Finally, it should be noted that all of the AR coefficient estimates are large and statistically significant, suggesting a strong influence of this short-term component. For coal the upper limit of the confidence interval is greater than one while for aggregate energy demand it is only marginally lower than one. This suggests that non-stationarity cannot be completely ruled out for these series. ${ }^{3}$

\subsection{Fractional integration results with seasonally filtered data: the X12 procedure}

Monthly data are often affected by seasonality effects, inertial factors related to the calendar. Seasonal effects are particularly clear in the autocorrelation and the partial autocorrelation functions for the final demand for electricity, gas and coal (see Appendix).

To address this issue, we use the seasonal adjustment methodology X-12 ARIMA, adopted by the U.S. Census Bureau [2011]. This strategy removes the seasonal effect to get a smoother time series for each final energy demand. We then estimated the ARFIMA model with the new seasonally adjusted data. Estimation results are presented in Table 4.

We find, that for all of the seasonally adjusted variables, the estimated fractional integration parameters are again statistically significant and within the interval $(0,0.5)$. Petroleum and its derivatives $(d=0.4956)$ and electricity $(d=0.4856)$ show the highest degrees of persistence closely followed by coal $(d=0.4449)$. Natural gas, in turn, shows a clearly lower level of persistence $(d=0.1508)$.

The confidence intervals for the fractional integration parameter at the aggregate final energy demand level and for petroleum and derivatives are very narrow while for natural gas it is relatively large. In all cases the lower bound of the confidence interval is positive. For electricity and coal, and more marginally for petroleum and its derivatives, the upper limits of the fractional-difference parameters are greater than

\footnotetext{
${ }^{3}$ It should be mentioned that in the ARFIMA framework, the short-run behavior of the series can be captured by the ARMA parameters while the long-run behavior can be modeled by the fractional differencing coefficient. Furthermore, the properties of the fractional integration parameter do not depend on the correct specification of the AR or MA terms. [Sowell (1992a and b) and Palma (2007)].
} 
Table 4 - Fractional integration results with seasonality-filtered data: X12 procedure

\begin{tabular}{|c|c|c|c|c|c|c|c|}
\hline & & \multirow{2}{*}{ Constant } & \multicolumn{2}{|r|}{ AR() } & \multirow{2}{*}{$\frac{\mathrm{FI}(\mathrm{)}}{\widehat{d}}$} & \multicolumn{2}{|r|}{ MA() } \\
\hline & & & $p$ & $\widehat{\boldsymbol{\rho}}$ & & $q$ & $\widehat{\boldsymbol{\theta}}$ \\
\hline \multirow{9}{*}{$\begin{array}{c}\text { Aggregate } \\
\text { energy } \\
\text { consumption }\end{array}$} & & 7.043 & 1 & 0.9851 & 0.4157 & 1 & -0.922 \\
\hline & Standard error & 0.8998 & & 0.03991 & 0.00042 & & 0.0268 \\
\hline & $p$-value & 0.000 & & 0.000 & 0.000 & & 0.000 \\
\hline & Conf. Interval (95\%) & {$[5,2795 ; 8,8065]$} & & {$[0,9083 ; 1,0619]$} & {$[0,4149 ; 0,4165]$} & & {$[-0,9745 ;-0,8695]$} \\
\hline & & & 2 & 0.0092 & & & \\
\hline & Standard error & & & 0.0382 & & & \\
\hline & $p$-value & & & 0.809 & & & \\
\hline & Conf. Interval (95\%) & & & {$[-0,0657 ; 0,0842]$} & & & \\
\hline & BIC & & & & & & \\
\hline \multirow{5}{*}{$\begin{array}{c}\text { Petroleum and } \\
\text { derivatives }\end{array}$} & & 6.8924 & & & 0.4956 & & \\
\hline & Standard error & 0.4904 & & & 0.0061 & & \\
\hline & $p$-value & 0.000 & & & 0.000 & & \\
\hline & Conf. Interval (95\%) & {$[5,9314 ; 7,8536]$} & & & {$[0,4836 ; 0,5075]$} & & \\
\hline & BIC & & & & & & \\
\hline \multirow{9}{*}{ Electricity } & & 5.3187 & 1 & 0.332 & 0.4856 & & \\
\hline & Standard error & 0.3618 & & 0.0604 & 0.0212 & & \\
\hline & $p$-value & 0.000 & & 0.000 & 0.000 & & \\
\hline & Conf. Interval (95\%) & {$[4,5097 ; 6,0278]$} & & {$[0,2137 ; 0,4529]$} & {$[0,4441 ; 0,5271]$} & & \\
\hline & & & 3 & 0.1659 & & & \\
\hline & Standard error & & & 0.0546 & & & \\
\hline & $p$-value & & & 0.000 & & & \\
\hline & Conf. Interval (95\%) & & & {$[0,2137 ; 0,4503]$} & & & \\
\hline & BIC & & & & & & \\
\hline \multirow{5}{*}{ Coal } & & 5.2126 & & & 0.4449 & & \\
\hline & Standard error & 0.4481 & & & 0.0348 & & \\
\hline & $p$-value & 0.000 & & & 0.000 & & \\
\hline & Conf. Interval (95\%) & {$[4,3343 ; 6,0910]$} & & & {$[0,3767 ; 0,5131]$} & & \\
\hline & BIC & & & & & & \\
\hline \multirow{5}{*}{ Gas } & & & 1 & 0.9922 & 0.1508 & & \\
\hline & Standard error & & & 0.0078 & 0.0626 & & \\
\hline & $p$-value & & & 0.000 & 0.018 & & \\
\hline & Conf. Interval (95\%) & & & {$[0,9770 ; 1,0075]$} & {$[0,028 ; 0,2734]$} & & \\
\hline & BIC & \multicolumn{6}{|c|}{104.480} \\
\hline
\end{tabular}

0.5 suggesting that the series may be non-stationary, though mean reverting.

The first order short-run seasonal AR coefficient estimates are all statically significant for a $5 \%$ test indicating that adjacent intertemporal dependence is also present. For the aggregate energy and more marginally for gas the upper limit of the confidence interval is greater the one, suggesting that non-stationarity cannot be completely ruled out for these two series. ${ }^{4}$

\subsection{Fractional integration with seasonality-adjusted data: the S12 procedure}

To directly account for seasonality, for each final energy demand component, we model the twelfth seasonal difference $\left(S 12 y_{t}=y_{t}-y_{t-12}=\left(1-L^{12}\right) y_{t}\right)$ of the

\footnotetext{
${ }^{4}$ Refer again to the previous footnote.
} 
Table 5 - Fractional integration with seasonality-adjusted data: the S12 procedure

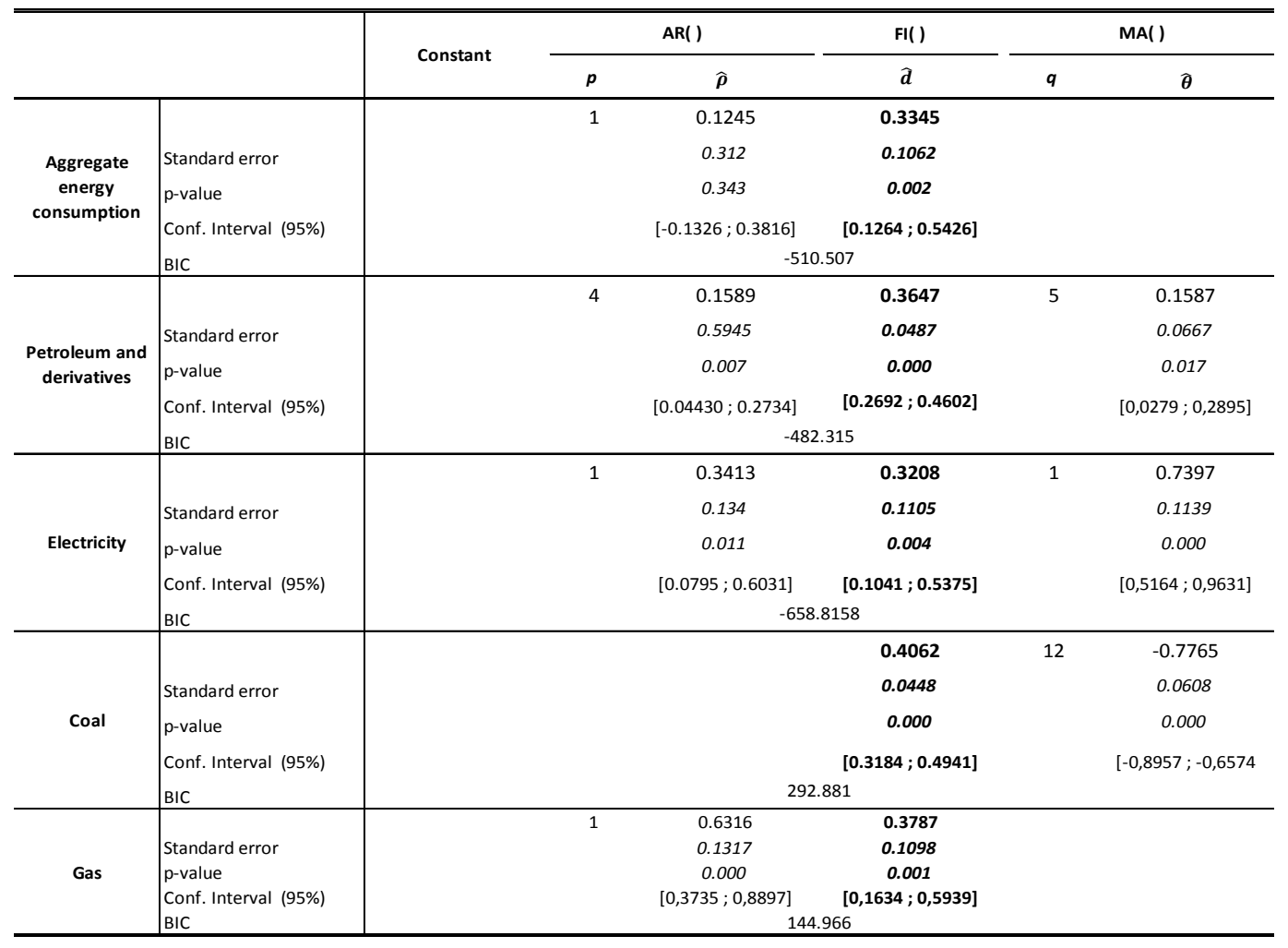

natural logarithm of the series and then (re)estimate the ARFIMA model. ${ }^{5}$ Accordingly, seasonality is long memory when $0<d_{s}<0.50$ and the short run dynamic is described through the estimation of the AR $\rho$ coefficient. Results are presented in Table 5.

All the " $d_{s}$ " fractional integration parameters range from 0.3345 to 0.4062 thereby rejecting both the pure seasonal stationary case and the seasonal unit root model. With the exception of coal, the confidence intervals are wide. For aggregate final energy consumption, electricity and gas, the upper limits of the fractional-difference parameters are greater than 0.5 suggesting that the series may be non-stationary, though mean reverting.

\footnotetext{
${ }^{5}$ A more general approach to seasonality would allow for fractional integration parameters to be different at different seasonal frequencies. See, for example, Hassler (1994) and Robinson (1994). In our case, we would like to argue that the S12 is a perfectly adequate approach. First, there is a clear monthly pattern that repeats itself annually. Second, the argument has been made that for reasons of parsimony the consideration of only one cycle of seasonality is preferable. See, for example, Ferrara and Guégan (2006).
} 
The short-run seasonal AR coefficient estimates are, in general, statistically significant for a $5 \%$ test indicating that adjacent intertemporal dependence is also present in final energy consumption. For aggregate final energy consumption the null (that is $\rho=0$ ) could not be rejected, suggesting that seasonal short memory is not present.

\section{Conclusions and Policy Implications}

Our empirical findings suggest that the presence of long memory cannot be rejected for either aggregate final energy demand or for each of its four components petroleum and its derivatives, electricity, coal, and natural gas. In addition, when we consider the issue of seasonality directly, our findings also indicate annual homologous seasonal long memory for all the components of final energy consumption. ${ }^{6}$

More specifically, all of the estimated fractional-integration parameters are positive and lower than 0.5. We can, therefore, reject both the pure stationary case $(d=0)$ and the unit root case $(d=1)$. All variables are stationary and mean reverting but with the autocorrelations decaying at a hyperbolic rate, that is, they exhibit long-term memory. Accordingly, despite the fact that the effects of temporary shocks tend to disappear only slowly, they preserve a temporary nature. In this sense, our results are in line with the evidence in the recent literature for the United States [see, for example, Lean and Smyth (2009), Gil-Alana, et al. (2010), Apergis and Tsoumas $(2011,2012)$ and Barros et al. (2012a and 2012b)].

To frame these results we also use the conventional approach of testing for the dichotomy between stationarity and non-stationarity. In this framework we would invariably conclude in favor of non-stationarity. Therefore, we would conclude that even transitory policy shocks would have permanent effects. Our fractional integration analysis highlights that this is not the case. The effects of transitory shocks are temporary, although long lasting. ${ }^{7}$

Understanding nature of persistence in the final energy consumption is a crucial issue as Portugal embarks work on the implementation of important environmental fiscal

\footnotetext{
${ }^{6}$ This finding highlights the importance of using monthly data and thereby one way in which this paper goes well beyond Belbute and Pereira (2014).

${ }^{7}$ This is another area in which this paper departs fundamentally from Belbute and Pereira (2014)]
} 
reforms aligned with both the EU strategy and UN green economy guidelines [see, for example, APA (2012) and CRFV (2014)].

Our findings on the long memory nature of final energy demand in Portugal have important implications for the design and the effectiveness of its energy and environmental policies. Persistence reflects strong habit formation mechanisms or technological rigidities. When final energy consumption is a pure stationary process, that is, a short memory process, then after a policy shock it will tend to move away from and revert to its trend more quickly than in presence of long memory, that is, a strong dependence on its past values.

Given the existence of long memory in energy consumption, positive policy shocks in the form, for example, of energy efficiency programs, subsidies for alternative renewable energy sources, or incentives for sustainable electrical mobility, are likely to be more effective because they tend to move energy consumption away from and revert to its predetermined target over a long period of time. This is the good news. The adoption of these programs has the potential to generate effects on energy demand patterns that go beyond the duration of the program.

But there is also bad news. Despite the fact that the effects of any active policy on energy consumption tend to disappear slowly, they preserve, however, their temporary nature. Permanent effects on final energy consumption will require a more permanent policy stance. Simply put, adopting programs only to ignore them or reverse them soon thereafter will not leave a permanent effect on demand patterns. Permanent results require permanent programs.

While it is not in the nature of this approach to make prescriptions about the adoption of any specific policy, our results are very informative in terms of what to expect from any existing or potential policy. On one hand, policies that are designed as temporary or end up being suspended cannot be expected to leave permanent effects. A case in point are the policies for 'green mobility' that pointed to the installation of charging stations for electric and hybrid vehicles and which was in the meantime abandoned without leaving any visible change in energy demand patterns. The same can be said about feed-in tariffs for photovoltaic generation, 
which had an important effect initially with generous rates but whose effects seem to have now petered out has their generosity has been severely curtailed.

On the other hand, policies that are either permanent or perceived as such will tend to generate strong and permanent effects. To illustrate this case we could consider the recently introduced carbon tax, which is designed as a permanent policy, and which as such has the potential for leading to substantive and permanent changes. Similarly, the long-lived feed in tariff programs for wind energy have left a clear and permanent mark in the sector.

Finally, these results have important implication from a more technical perspective. They suggest the importance of accounting for the energy-economy interactions both in terms of modeling and energy forecasting as shocks in energy demand exhibit long memory and will tend to reverberate throughout the economy. Natural gas seems to be less of an issue in this context given its relatively lower levels of persistence.

Although these are important implications in the Portuguese context, though they are far from parochial. In fact, understanding persistence in final energy consumption is imperative, for example, in the European Union. At the core of the renewed policy focus in the EU is the idea that public policy for a green economy should extend well beyond the usual "getting prices right" in order to shift consumption and production patterns to a more sustainable path of greenhouse gas emissions and reduced energy dependency [see, for example, EC (2011, 2013, 2014a, 2014b].

\section{References}

Agência Portuguesa do Ambiente [APA] (2012). "A National Roadmap to Low Carbon 2050," Ministério da Agricultura, do Mar, do Ambiente e do Ordenamento do Território, Lisboa, Portugal.

Altinay, G. and E. Karagol (2004). "Structural break, unit root and the causality between energy consumption and GDP in Turkey," Energy Economics 26, 985-94.

Aloy, M., M. Boutahar, K. Gente and A. Feissolle (2011). "Purchasing power parity and the long memory properties of real exchange rates: Does one size fit all?" Economic Modelling 28, 1279-90.

Apergis, N. and C. Tsoumas (2011). "Integration properties of disaggregated solar, geothermal and biomass energy consumption in the US," Energy Policy 39, 5474-79. 
Apergis, N. and C. Tsoumas (2012). "Long memory and disaggregated energy consumption: evidence from fossil fuels, coal and electricity retail in the US," Energy Economics 34, 1082-87.

Apergis, N. and J. Payne (2010). "Structural breaks and petroleum consumption in US states: are shocks transitory or permanent?," Energy Policy 38, 6375-78.

Aslan, A. and H. Kum (2011). "The stationarity of energy consumption for Turkish disaggregate data by employing linear and nonlinear unit root tests," Energy 36, 4256-58.

Baillie R. T. (1996). "Long Memory and Fractional Integration in Econometrics," Journal of Econometrics 73, 5-59.

Backus, D. and S. Zin (1993); "Long-Memory Inflation Uncertainty: Evidence from the Term Structure of Interest Rates," Journal of Money, Credit and Banking, (25) 3 part 2, pp 681-700.

Bos, C. S. Koopman and M. Ooms (2014). "Long memory with stochastic variance model: A recursive analysis for US inflation," Computational Statistics \& Data Analysis 76, 144-57.

Barros, C., L. Gil-Alana e L. Payne (2012a). "Evidence of long memory behavior in US renewable energy consumption," Energy Policy 41, 822-6.

Barros, C., G. Caporale and L. Gil-Alana (2012b). "Long Memory in German Energy Price Indices," Deutsches Institut für Wirtschaftsforschung Berlim (DIW Berlin) Discussion paper 1186, Berlin.

Belbute, J. and A.Pereira (2015a); "An alternative reference scenario for global CO2 emissions from fuel consumption: An ARFIMA approach", Economics Letters 136, 108-111.

Belbute, J. and A.Pereira (2015b); "Do Global CO2 Emissions from Fuel Comsumption Exhibit Long Memory? A Fractional Integration Approach", College of William and Mary Economics Department Working Paper 164.

Caporale GM, Gil-Alana LA (2004). "Testing for seasonal fractional roots in the German real output," German Economic Review 5, 319-33.

Cheung, Yin-Wong (1993). "Long-memory in foreign-exchange rates," Journal of Business \& Economic Statistics 11, 93-101.

Comissão da Reforma da Fiscalidade Verde [CRFV] (2014). "Projecto de Reforma da Fiscalidade Verde," Ministério do Ambiente do Ordenamento do Território e da Energia, Lisboa, Portugal.

Diebold and Rudebush (1989). "Long memory and persistence in aggregate output," Journal of Monetary Economics 21, 89-209.

Dijk, D., P. Hans and R. Paap (2002). "A nonlinear long memory model with an application to US unemployment," Journal of Econometrics 110, 135-65.

Elder, J. and A. Serletis (2008). "Long memory in energy futures prices," Review of Financial Economics 17, 146-55. 
European Commission (2011). "Energy Roadmap 2050," Communication from the commission, http://ec.europa.eu/energy/energy2020/roadmap/index en.htm.

European Commission (2013). "Green Paper - A 2030 Framework for Climate and Energy Policies," Communication from the commission, http://eur-lex.europa.eu/legal-content/EN/TXT/?uri=celex:52013DC0169.

European Commission (2014a). "Progress Towards Achieving Kyoto and EU 2020 Objectives," Report from the Commission to the European Parliament and the Council, http://eur-lex.europa.eu/legal-content/EN/TXT/?uri=CELEX:52013DC0698

European Commission (2014b). "A Policy Framework for Climate and Energy in the Period 2020 up to 2030," Communication from the Commission, http://eur-lex.europa.eu/legal-content/EN/TXT/?uri=CELEX:52014DC0015

Ferrara, L. and D. Guégan (2006); "Fractional Seasonality: Models and Applications to Economic Activity in the Euro Area," in Euro Indicators Papers Collection, Eurostat Publications, Luxembourg.

Gil-Alana L., D. Loomis and J. Payne (2010); "Does Energy Consumption by the US Electric Power Sector Exhibit Long Memory Behavior?" Energy Policy 38, 75157518.

Gil-Alana, L. (2010). "A seasonal fractional multivariate mode; A testing procedure and impulse responses for the analysis of GDP and unemployment dynamics," Empirical Economics 38, 471-501.

Gil-Alana, L. (2002). "Structural breaks and fractional integration in the US output and unemployment rate," Economics Letters 77, 79-84.

Granger C.W.J. (1980). "Long Memory Relationships and the Aggregation of Dynamic Models," Journal of Econometrics 14, pp. 227-38.

Granger C.W.J. (1981). "Some Properties of Time Series Data and their Use in Econometric Model Specification," Journal of Econometrics 16, 121-30;

Granger C.W.J. and R. Joyeux (1980). "An Introduction to Long Memory Time Series and Fractional Differencing," Journal of Time Series Analysis 1, 15-29;

Hasanov, M. e Telatar (2011). "A re-examination of stationarity of energy consumption: evidence from new unit root tests," Energy Policy 39, 7726-38.

Hassler, U. (1994). "Misspecification of long memory seasonal time series," Journal of Time series Analysis 15, 19-30.

Hsu, Y. and C-C Lee (2008). "Revisited: are shocks to energy consumption permanent or stationary? New evidence from a panel SURADF approach," Energy Economics 30, 2314-30.

Lean, H. and R. Smyth (2009). "Long memory in US disaggregated petroleum consumption: Evidence from univariate and multivariate LM tests for fractional integration," Energy Policy 37, 3205-11.

Lee, C e C. Chang (2005). "Structural breaks, energy consumption and economic growth revisited: Evidence from Taiwan," Energy Economics 27, 857-72; 
Lee, C. and C. Chang (2008). "Energy consumption and economic growth in Asian economies: a more comprehensive analysis using panel data," Resource and Energy Economics 30, 50-65;

Lee, C. and J. Lee (2009); "Energy prices, multiple structural breaks and efficient market hypothesis," Applied Energy, 86, 466-479.

Lo, A (1991). "Long-term memory in stock market prices," Econometrica 59, 1279-313.

Narayan, P. S. Narayan and S. Popp (2010). "Energy consumption at the state level: the unit root null hypothesis from Australia," Applied Energy 87, 1953-62.

Narayan, P., S. Narayan and R. Smyth (2008). "Are oil shocks permanent or temporary? Panel data evidence from crude oil and NGL production in 60 countries," Energy Economics 30, 919-36.

Narayan, P. and R. Smyth (2005). "Electricity consumption, employment and real income in Australia: evidence from multivariate granger causality tests," Energy Policy 33, 1109-16.

Narayan, P. and R. Smyth (2007). "Are shocks to energy consumption permanent or temporary: evidence from 182 countries," Energy Policy 35, 333-41.

Palma (2007). Long-Memory Times Series: Theory and Methods, Hoboken, Wiley.

Pereira and Belbute (2014); "Final Energy Demand in Portugal: How Persistent it is and Why it Matters for Environmental Policy,"International Economic Journal, 28 (4), pp. 661-677;

Porter-Hudak, S. (1990). "An application of the seasonally fractionally differenced model to the monetary aggregates," Journal of the American Statistical Association $85,338-44$.

Ray, B. (1993). "Long-range forecasting of IBM product revenues using a seasonal fractionally differenced ARMA model," International Journal of Forecasting 9, 25569.

Robinson (1994). "Efficient tests of non-stationary hypothesis," Journal of the American Statistical Association 89, 1420-57.

SinclairTM (2005). "Permanent and transitory movements in output and unemployment: Okun's law persists," Washington University Working Paper St. Louis.

Smyth, R. (2012). "Are Fluctuations in Energy Variables Permanent or Transitory? A Survey of the Literature on the Integration Properties of Energy Consumption and Production," Discussion Paper 4/12, Department of Economics, Monash University, Australia.

Sowell, F. (1992a). "Modeling Long-run behavior with the fractional ARIMA model," Journal of Monetary Economics 29, 277-302.

Sowell F. (1992b). "Maximum Likelihood Estimation of Stationary Univariate Fractionally Integrated Time Series Models," Journal of Econometrics 53, 165-88.

U.S. Census Bureau (2011). “ X-12-ARIMA Reference Manual,” Version 0.3, X-12-ARIMA Seasonal Adjustment Program 
https://www.census.gov/srd/www/winx12/winx12 down.html

Willinger, W., M. Taqqu and V. Teverovsky (1999). "Stock price return indices and long-range dependence," Finance and Stochastics 3, 1-13.

Yoon, G. (2009). "Purchasing power parity and long memory," Economic Letters 9, 5561. 


\section{APPENDIX \\ Auto-correlation and partial auto-correlation functions}

(log-levels)
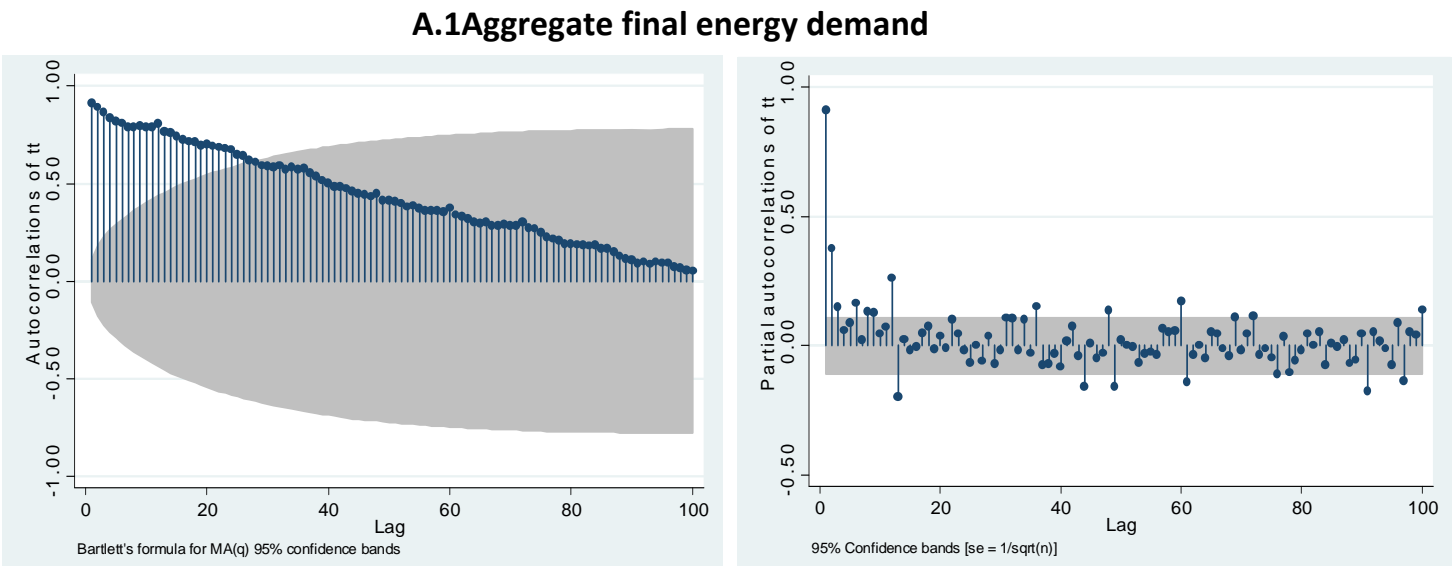

A.2 Petroleum and its derivatives
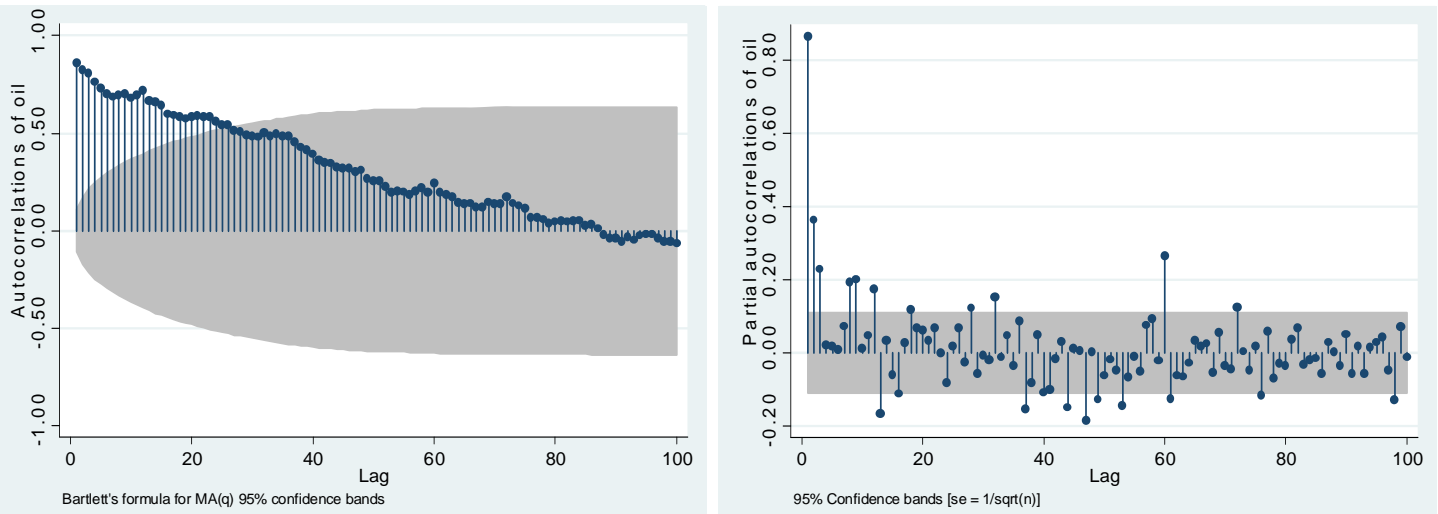

\section{A.3 Electricity}
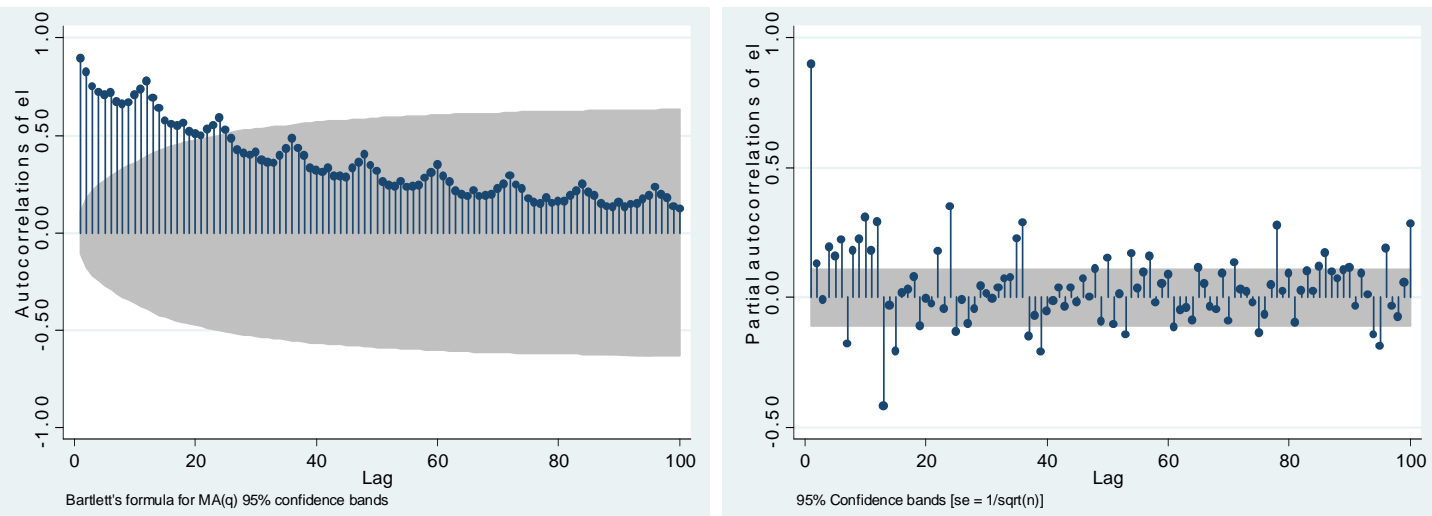


\section{A.4 Coal}
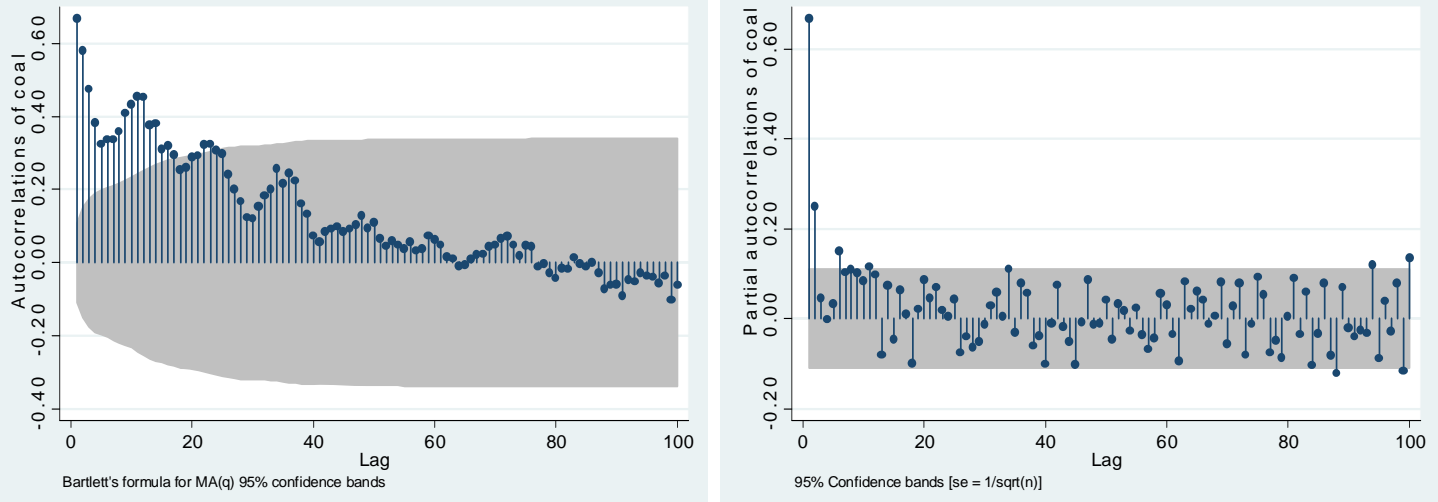

\section{A.5 Natural gas}
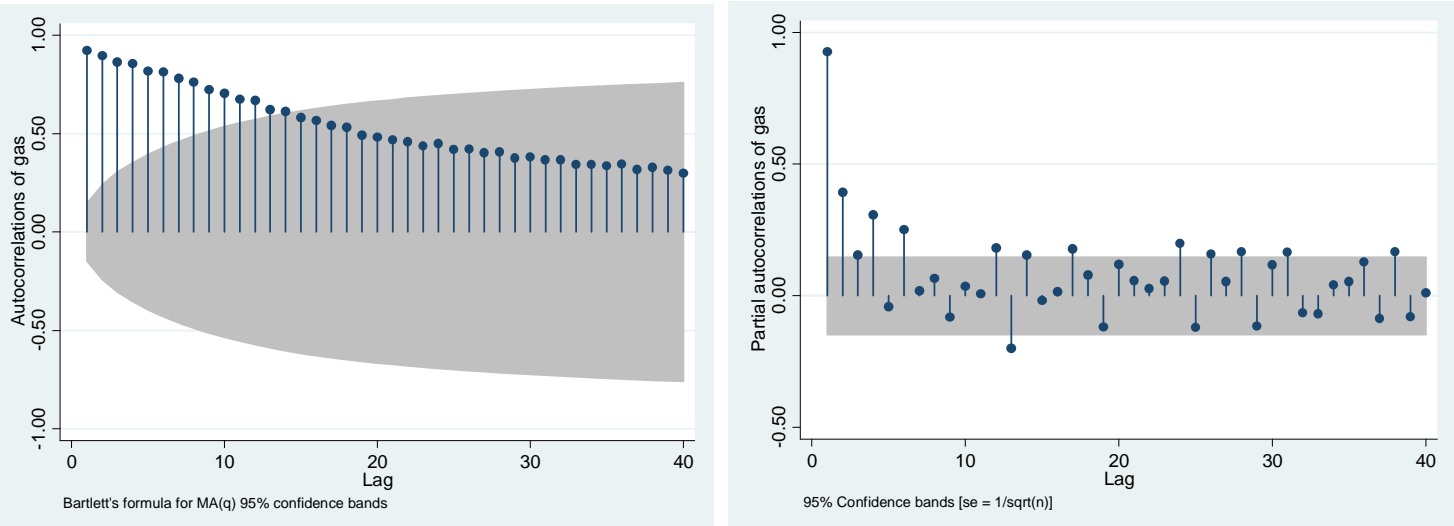